\title{
Analyzing the Usability of University's Websites in Sumatera Using the Technique for Order Preference by Similarity to Ideal Solution (TOPSIS) Method
}

\section{Analisa Usability Website Perguruan Tinggi di Sumatera Menggunakan Metode Technique for Order Preference by Similarity to Ideal Solution (TOPSIS)}

Ozzy Secio Riza ${ }^{1 *}$, Novia Lestari ${ }^{1}$, Nurjanah $^{1}$

\begin{abstract}
This study was carried out to analyze the quality of college websites in Sumatra in terms of usability of the website. Results of the analysis presented as ranking using TOPSIS method. The object of this study was five university websites in Sumatra, Lampung University (UNILA), Medan State University (UNIMED), Andalas University (UNAND) Padang State University (UNP), and Sriwijaya University (UNSRI) with 7 criteria including accessibility, customization and personalization, download speed, ease of use, errors, navigation, and site content. Results of the research that has been calculated then ranked using TOPSIS. The results of the research show that UNAND's website has the most excellent usability with value similarity to the ideal solution is 0.707. Compared with webometrics' rank released in July 2021, there is a difference in ratings. Such differences may occur because the study was measuring the usability of its website and using TOPSIS method while webometrics uses different indicators.
\end{abstract}

Keywords

Usability, University Website, TOPSIS, Webometrics Rank

\begin{abstract}
Abstrak
Penelitian ini menganalisa kualitas website beberapa universitas di Sumatera ditinjau dari usability website. Hasil analisis disajikan dalam bentuk rangking dengan menggunakan metode TOPSIS. Objek penelitian ini merupakan website Perguruan Tinggi di Sumatera, yaitu Universitas Lampung (UNILA), Universitas Negeri Medan (UNIMED), Universitas Andalas (UNAND) Universitas Negeri Padang (UNP), dan Universitas Sriwijaya (UNSRI). Hasil penelitian menunjukkan bahwa website UNAND memiliki usability yang paling baik dengan nilai similarity to ideal solution adalah 0,707 . Dibandingkan dengan peringkat webometrics, terdapat perbedaan peringkat. Perbedaan tersebut dapat terjadi karena penelitian mengukur usability website dan menggunakan TOPSIS, sedangkan webometrics menggunakan indikator berbeda.
\end{abstract}

\section{Kata Kunci}

usability website, website perguruan tinggi, TOPSIS, Webometrics Rangking.

${ }^{1}$ Prodi Sistem Informasi, UIN Imam Bonjol Padang

Balai Gadang, Koto Tangah, Kota Padang

*ozzysecioriza@uinib.ac.id

Submitted : January 19, 2022. Accepted : February 22, 2022. Published : February 25, 2022. 


\section{PENDAHULUAN}

Pada era digital, Perguruan Tinggi sudah seharusnya memiliki sebuah website. Website berisikan halaman yang memuat berbagai macam informasi mengenai lembaga yang dalam hal ini adalah perguruan tinggi. Karena website berperan penting untuk memberikan informasi mengenai perguruan tinggi kepada masyarakat, maka dibutuhkan evaluasi kualitas website agar proses publikasi tetap berjalan. Website sangat berguna mendukung user dan memungkinkan user untuk mencapai tujuan mereka dengan cepat, efisien, dan simpel [1].

Saat ini telah ada pengukuran online untuk kualitas website perguruan tinggi di seluruh dunia, disebut webometrics. Webometrics meranking website perguruan tinggi di seluruh dunia. Webometrics berkaitan dengan halaman website serta konten yang berada didalamnya [2]. Webometrics menggunakan visibility, transparency, dan excellence sebagai indikator untuk mendapatkan hasil perangkingan.

Pada saat sekarang ini belum ada perangkingan kualitas website yang menjadikan usability sebagai indikatornya, padahal usability merupakan bagian penting dalam pengukuran kualitas website. Usability website merupakan salah satu faktor yang sangat penting agar sebuah situs dapat bertahan [3].

Usability didefinisikan sebagai sejauh mana suatu produk atau pelayanan mampu menjamin kepuasan, efisiensi, dan efektivitas bila digunakan oleh berbagai jenis pengguna [4]. Usability website merupakan kualitas pengalaman user ketika berinteraksi dengan produk yang dalam hal ini adalah website, terkait juga dengan penyajian informasi dengan cara yang ringkas dan jelas.

Data yang diperoleh dari webometrics periode pengukuran Januari 2022 menunjukkan bahwa perguruan tinggi di Sumatera tidak berada di peringkat 5 besar kualitas website perguruan tinggi di Indonesia dari 2585 kualitas website perguruan tinggi Indonesia yang dibandingkan. Peringkat tertinggi perguruan tinggi di Sumatera diraih oleh Universitas Lampung yang berada di peringkat 10 Indonesia dan 1817 di dunia.

Dalam penelitian ini penulis akan menganalisis usability website akademik Perguruan Tinggi di Sumatera kemudian merangking website perguruan tinggi tersebut menggunakan metode TOPSIS. Metode TOPSIS pada umumnya dimanfaatkan untuk menyelesaikan masalah keputusan [5][6]. Penelitian terdahulu [7] menggunakan metode TOPSIS untuk membuat sistem pendukung keputusan untuk memilih siswa berprestasi. Kemudian [8] menggunakan TOPSIS untuk merangking siswa dalam ajang penghargaan.

Penelitian sebelumnya yang membahas mengenai usability website mengukur usability website Politeknik Negeri Sriwijaya. Metode yang digunakan adalah System Usability Scale dengan menyebar kuesioner [9], sedangkan [10] menganalisa usability website Traveloka.com. [11] mengevaluasi usability website Universitas Muhammadiyah Magelang. Metode yang digunakan adalah metode kuantitatif dengan menyebar kuesioner. [12] merangking website toko buku online dari segi usability website, [13] menganalisa usability web HRMIS Telkom University menggunakan usability testing.

Tujuan dari penelitian ini adalah mengukur aspek usability dari website perguruan tinggi di Sumatera menggunakan metode TOPSIS.

\section{METODE PENELITIAN}

Penelitian dilakukan dengan mengumpulkan data masing - masing kriteria terkait usability website. Data yang didapatkan kemudian dianalisis untuk mendapatkan nilai hasil penelitian menggunakan metode TOPSIS. Metode tersebut digunakan untuk meranking objek penelitian.

\section{Kriteria Usability}

Terdapat beragam kriteria yang dapat digunakan untuk mengukur usability dari sebuah website. [10][11] menggunakan Learnability, Memorability, Efficiency, Errors, dan Satisfaction. 
[12] menggunakan tujuh kriteria usability website yang merujuk pada [14][15]. Dalam penelitian ini akan digunakan tujuh kriteria yang digunakan oleh [12], yaitu:

1. Accessibility, yaitu seberapa jauh website dapat diakses oleh orang - orang yang membutuhkan lebih dari web browser tradisional untuk men-akses internet [16].

2. Customization \& Personalization, sebuah website dituntut untuk menyediakan layanan atau produk yang menyesuaikan kebutuhan pengguna. Karakteristik dari suatu website

3. Download Speed, merupakan waktu respon atau download delay [17]. Dapat dikatakan juga sebagai berapa lama sebuah website dapat diakses seluruh konten didalamnya secara penuh.

4. Ease of Use, merupakan usaha yang dilakukan pengguna untuk mengakses website.

5. Errors, merupakan jumlah error yang didapatkan pengguna selama mengakses website. Hal yang akan diperhatikan adalah link yang rusak pada suatu website.

6. Navigation, merupakan elemen desain yang penting, yang memungkinkan pengguna untuk mendapatkan lebih banyak informasi yang mereka cari dan membuat informasi lebih mudah untuk ditemukan [17].

Site Content, merupakan informasi yang didapatkan oleh pengguna saat mengakses sebuah website, berkaitan juga dengan kualitas dari informasi yang didapatkan [17]. Penelitian ini akan menghitung file ber-ekstensi .pdf/.doc/.ppt yang terdapat pada website dan terindeks oleh search engine.

Dalam penelitian kali ini digunakan lima belas (14) online tools untuk mendapatkan data yang dibutuhkan. Tabel 1 menunjukkan daftar online tools yang digunakan pada penelitian ini:

Tabel 1. Daftar online tools kriteria usability

\begin{tabular}{|c|c|c|c|}
\hline No & $\begin{array}{c}\text { Kriteria Usability } \\
\text { Website }\end{array}$ & Online Tools & Hasil Pengukuran \\
\hline \multirow[t]{2}{*}{1} & \multirow[t]{2}{*}{ Accessibility } & a. validator.w3.org & \multirow[t]{2}{*}{ Number of errors } \\
\hline & & b. wave.webaim.org & \\
\hline 2 & $\begin{array}{l}\text { Customization \& } \\
\text { Personalization }\end{array}$ & www. statshow.com & $\begin{array}{l}\text { Jumlah } \\
\text { Pengunjung }\end{array}$ \\
\hline \multirow[t]{2}{*}{3} & \multirow[t]{2}{*}{ Download Speed } & a. gtmetrix & \multirow[t]{2}{*}{ Kecepatan loading } \\
\hline & & b. pingdom.com & \\
\hline \multirow[t]{2}{*}{4} & \multirow[t]{2}{*}{ Ease of Use } & a. jigsaw.w3.org/css-validator/ & \multirow[t]{2}{*}{ Number of errors } \\
\hline & & b. codebeautify.org/cssvalidate & \\
\hline \multirow[t]{3}{*}{5} & \multirow[t]{3}{*}{ Error } & a. http://validator.w3.org/checklink & \multirow[t]{3}{*}{ Jumlah link rusak } \\
\hline & & $\begin{array}{l}\text { b. https://www.brokenlinkcheck.com/broke } \\
\text { n-links.php }\end{array}$ & \\
\hline & & c. deadlinkchecker.com/ & \\
\hline \multirow[t]{2}{*}{6} & \multirow[t]{2}{*}{ Navigation } & a. https://ahrefs.com/backlink-checker & \multirow[t]{2}{*}{ Jumlah link website } \\
\hline & & b. http://www.exalead.com/search/ & \\
\hline \multirow[t]{3}{*}{7} & \multirow[t]{3}{*}{ Site Content } & a. yahoo.com & \multirow{3}{*}{$\begin{array}{l}\text { Jumlah file yang } \\
\text { terindeks }\end{array}$} \\
\hline & & b. bing.com & \\
\hline & & c. google.co.id & \\
\hline
\end{tabular}

Data penelitian diambil secara online selama 7 hari berturut - turut. Setelah didapatkan data hasil penelitian selama 7 hari menggunakan 15 online tools, kemudian ditarik nilai rata rata.

Metode perangkingan menggunakan TOPSIS. Pertama, seluruh data yang didapatkan akan dinormalisasi agar mudah dalam proses analisis. Dalam menentukan solusi ideal positif dan 
solusi ideal negatif perlu diperhatikan karakter suatu kriteria, yaitu benefit criteria dan cost criteria.

Dikatakan cost criteria jika kriteria dikatakan baik jika nilai ktiteria tersebut semakin kecil, yaitu accessibility, ease of use, error, dan download speed. Kriteria dikatakan benefit criteria apabila dikatakan baik jika nilai kriteria semakin besar, yaitu customization \& personalization, navigation, dan site content. Tahapan dalam Metode TOPSIS adalah:

1. Buat matriks keputusan ternormalisasi

$r_{i j}=\frac{x_{i j}}{\sqrt{\sum_{i=1}^{m} x_{i j}^{2}}}$,dengan $\mathrm{i}=1,2,3, \ldots, \mathrm{m} ;$ dan $\mathrm{j}=1,2,3, \ldots, \mathrm{n}$;

$\mathrm{r}_{\mathrm{ij}}=$ bagian dari matriks ternornalisasi $\mathrm{r}$

$\mathrm{x}_{\mathrm{ij}}=$ bagian dari matriks keputusan $\mathrm{x}$

2. Buat matriks keputusan ternormalisasi terbobot

Dengan bobot $\mathrm{w}_{\mathrm{j}}=\left(\mathrm{w}_{1}, \mathrm{w}_{2}, \mathrm{w}_{3}, \ldots, \mathrm{w}_{\mathrm{n}}\right)$, dimana $\mathrm{w}_{\mathrm{j}}$ merupakan bobot kriteria ke-j dan $\sum_{j=1}^{n} w_{j}=1$, normalisasi bobot matriks $\mathrm{V}$ adalah:

$y_{i j}=w_{j} r_{i j}$, dengan $\mathrm{i}=1,2,3, \ldots, \mathrm{m}$; dan $\mathrm{j}=1,2,3, \ldots, \mathrm{n}$.

$y_{i j}=$ matriks keputusan ternormalisasi terbobobot

$w_{j}=$ bobot kriteria ke-j

$r_{i j}=$ bagian dari matriks keputusan ternormalisasi $\mathrm{r}$

3. Buat matriks solusi ideal positif $\mathrm{A}^{+}$dan negatif $\mathrm{A}^{-}$

a. $A^{+\left\{\left(\operatorname{maxy}_{i j} \mid j \in J\right),\left(\min _{i j} \mid j \in J^{\prime}\right), i=1,2,3, \ldots, m\right\}=}$

b. $A^{-=\left\{\left(\operatorname{miny}_{i j} \mid j \in J\right),\left(\operatorname{maxy}_{i j} \mid j \in J^{\prime}\right), i=1,2,3, \ldots, m\right\}=}$

$\mathrm{J}=\{\mathrm{j}=1,2,3, \ldots, \mathrm{n}$ dan $\mathrm{J}$ merupakan benefit criteria $\}$.

$\mathrm{J}^{\prime}=\left\{\mathrm{j}=1,2,3, \ldots, \mathrm{n}\right.$ dan $\mathrm{J}^{\prime}$ merupakan cost criteria $\}$.

Keterangan:

$y_{i j}$ adalah elemen dari matriks keputusan yang ternormalisasi terbobot $\mathrm{V}$,

$y_{1}^{+}(j=1,2,3, \ldots, n) ; y_{1}^{-}(j=1,2,3, \ldots, n)$ adalah elemen matriks solusi ideal positif dan negatif.

4. Tentukan jarak antara nilai setiap alternatif dengan matriks solusi ideal positif dan negatif.

a. $\mathrm{D}^{+}$adalah jarak alternatif dari solusi ideal positif didefinisikan sebagai:

$D_{i}^{+}=\sqrt{\sum_{j=1}^{n}\left(y_{i j}-y_{j}^{+}\right)^{2}}$, dengan $\mathrm{i}=1,2,3, \ldots, \mathrm{m}$

b. D- adalah jarak alterntif dari solusi ideal negatif didefenisikan sebagai:

$D_{i}^{-}=\sqrt{\sum_{j=1}^{n}\left(y_{i j}-y_{j}^{-}\right)^{2}}$, dengan $\mathrm{i}=1,2,3, \ldots, \mathrm{m}$

Keterangan:

$D_{i}^{+} ; D_{i}^{-}$adalah jarak alternatif ke-1 dari solusi ideal positif dan negatif

$y_{i j}$ adalah elemen dari matriks keputusan yang ternormalisasi terbobot $\mathrm{V}$

$y_{j}^{+} ; y_{j}^{-}$adalah elemen matriks solusi ideal positif dan negatif

5. Tentukan nilai preferensi untuk setiap alternatif 
Kedekatan relatif dari setiap alternatif terhadap solusi ideal positif dapat dihitung dengan menggunakan persamaan berikut:

Dengan $\mathrm{i}=1,2,3, \ldots, \mathrm{m}$

$$
V_{i}=\frac{D_{i}^{-}}{\left(D_{i}^{-}+D_{i}^{+}\right)}
$$

Keterangan:

$V_{i}$ adalah kedekatan relatif dari alternatif ke-I terhadap solusi ideal positif,

$D_{i}^{+} ; D_{i}^{-}$adalah jarak alternatif ke-I dari solusi ideal positif dan negatif.

\section{HASIL DAN PEMBAHASAN}

Data hasil pengukuran kriteria usability website, yang diteliti pada tanggal 12 Januari 2021 sampai 18 Januari 2021 menggunakan 15 online tools dapat dilihat pada Gambar 1.

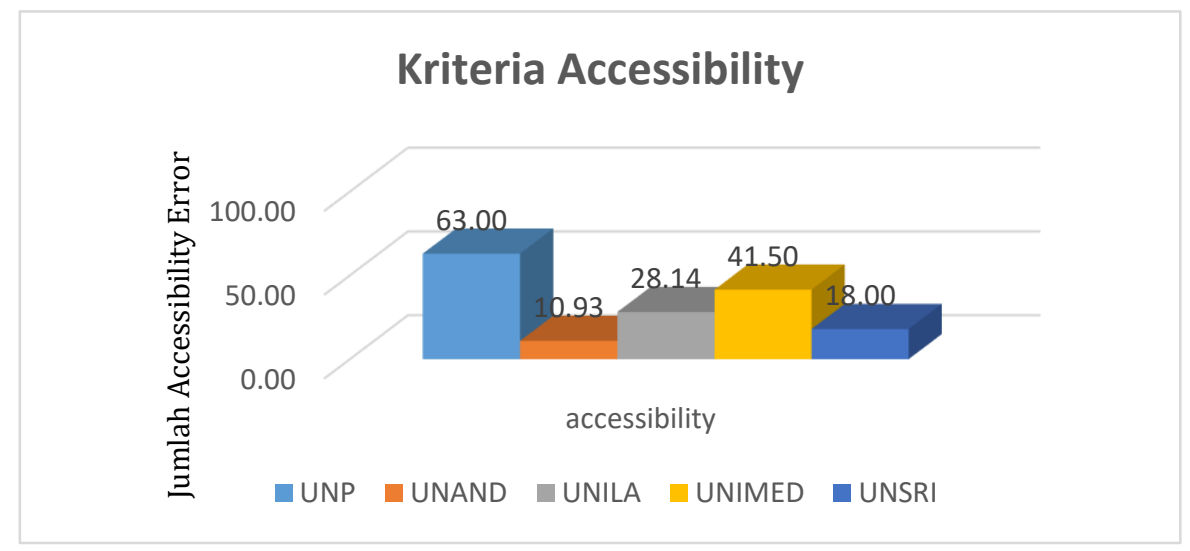

Gambar 1. Grafik Hasil Pengukuran Accessibility Error

Berdasarkan gambar 1 dapat dilihat bahwa website Universitas Andalas memiliki tingkat accessibility paling baik dengan jumlah masalah terendah dibandingkan website perguruan tinggi lainnya yaitu terdapat rata - rata 10,93 masalah. Sedangkan website dengan masalah accessibility terbesar adalah website Universitas Negeri Padang denga rata - rata 63 masalah.

Berdasarkan gambar 2 dapat dilihat bahwa website Universitas Sriwijaya memiliki rata rata jumlah pengunjung paling banyak dibandingkan dengan website perguruan tinggi lainnya, yaitu 7980 pengunjung. Sedangkan untuk wesite Universitas Negeri Medan memiliki jumlah rata - rata terendah dengan 1198 pengunjung.

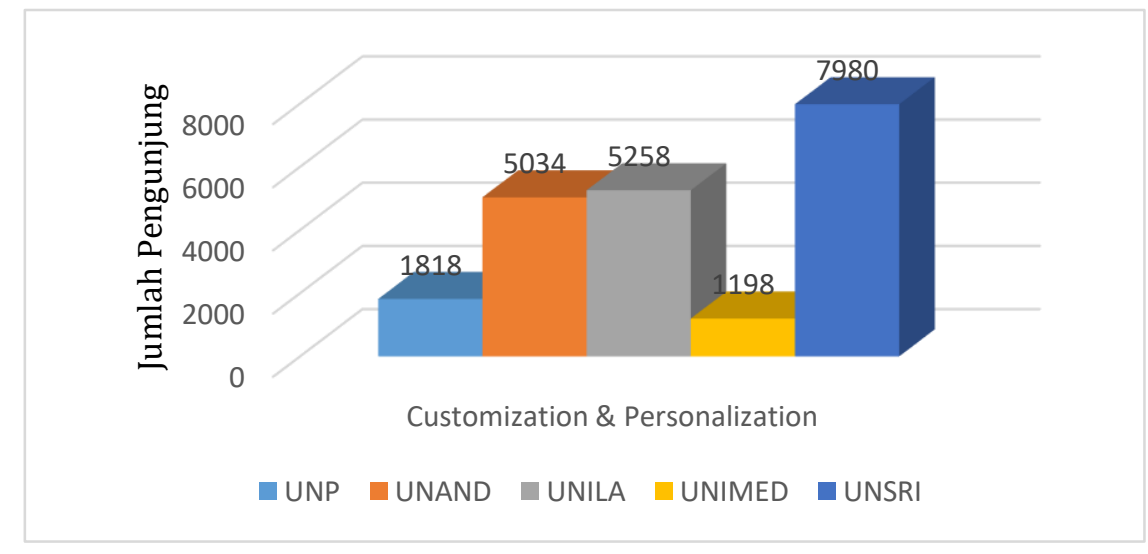

Gambar 2. Grafik Hasil Pengukuran Customization \& Personalization

Berdasarkan gambar 3 dapat dilihat bahwa website Universitas Sriwijaya memiliki kecepatan loading paling baik dengan waktu loading tersingkat dibandingkan website 
perguruan tinggi lainnya yaitu rata - rata 4,44 detik. Sedangkan website website dengan waktu loading terlama adalah website Universitas Andalas dengan waktu loading rata - rata 13,62 detik

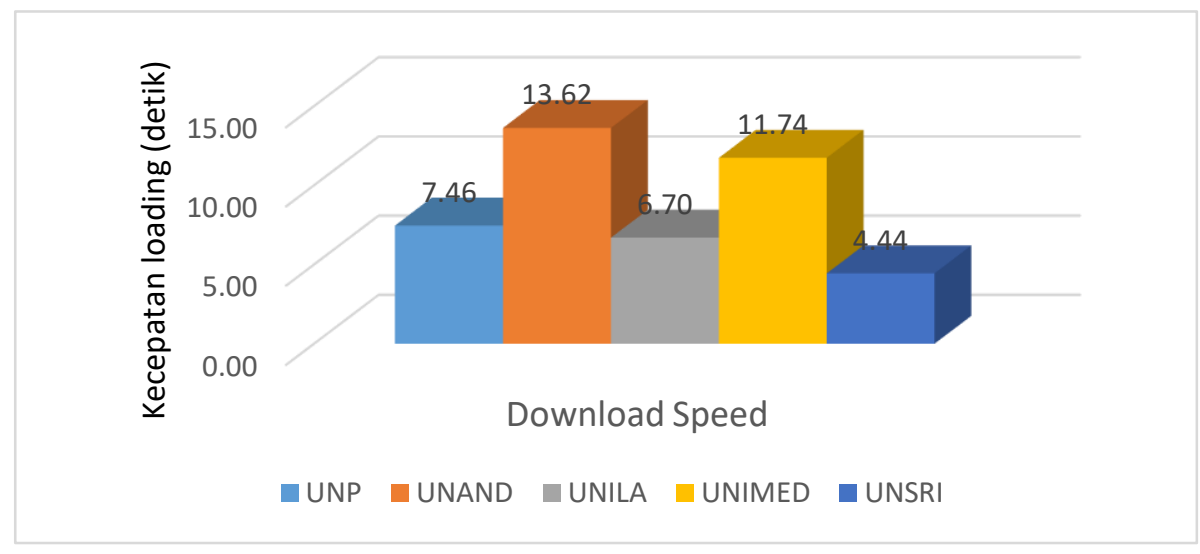

Gambar 3. Grafik Hasil Pengukuran Download Speed

Berdasarkan gambar 4 dapat dilihat bahwa website Universitas Negeri Padang paling baik untuk kriteria ease of use. Hal tersebut dapat dilihat dengan jumlah error pada struktur CSS website paling sedikit dibandingkan website perguruan tinggi lainnya yaitu terdapat rata - rata 37,5 error. Sedangkan website yang memiliki jumlah error terbanyak adalah Universitas Negeri Medan dengan rata - rata 462,5 error.

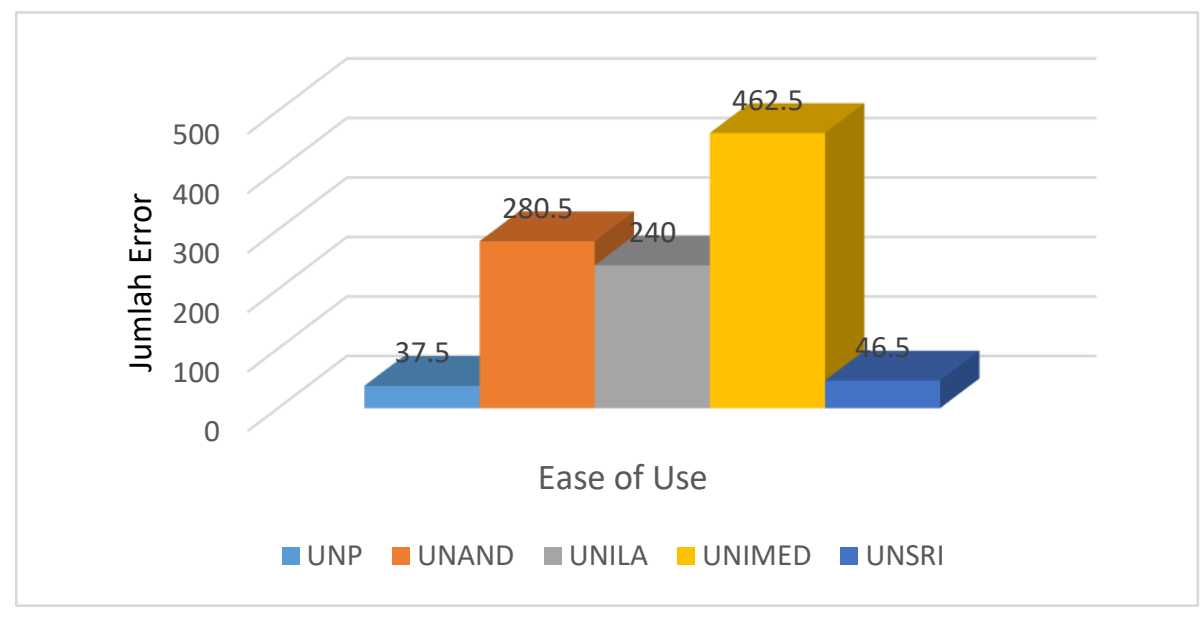

Gambar 4. Grafik Hasil Pengukuran Ease of Use

Berdasarkan gambar 5 dapat dilihat bahwa website Universitas Sriwijaya paling baik untuk kriteria error dengan jumlah link yang rusak paling sedikit dibandingkan website perguruan tinggi lainnya yaitu terdapat rata - rata 21,95 link. Sedangkan website dengan jumlah link rusak terbanyak adalah website Universitas Andalas dengan rata - rata 85,95 link rusak.

Berdasarkan gambar 6, website Universitas Negeri Lampung paling baik untuk kriteria navigation dengan jumlah link paling banyak dibandingkan website perguruan tinggi lainnya yaitu terdapat rata - rata 3451280,64 link. Sedangkan website Universitas Negeri Padang memiliki jumlah rata - rata terendah dengan 497280,43 link. 


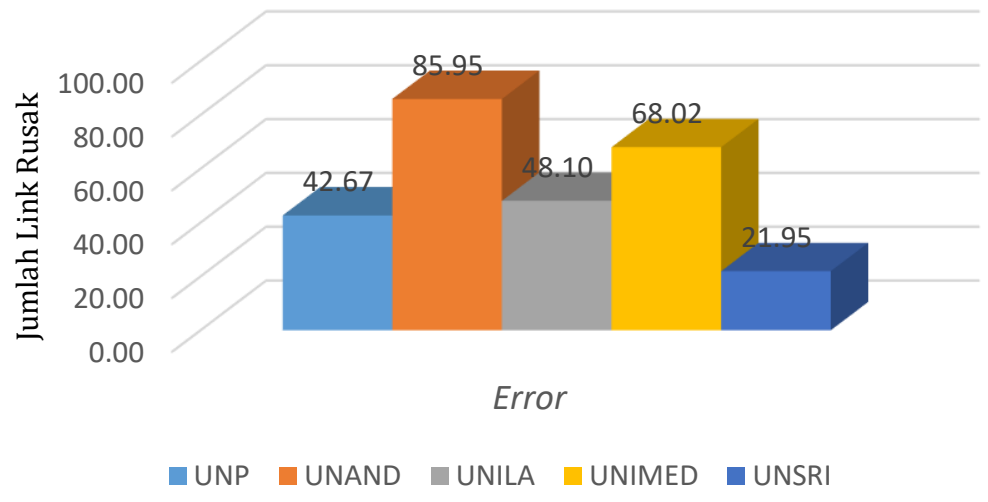

Gambar 5. Grafik Hasil Pengukuran Error

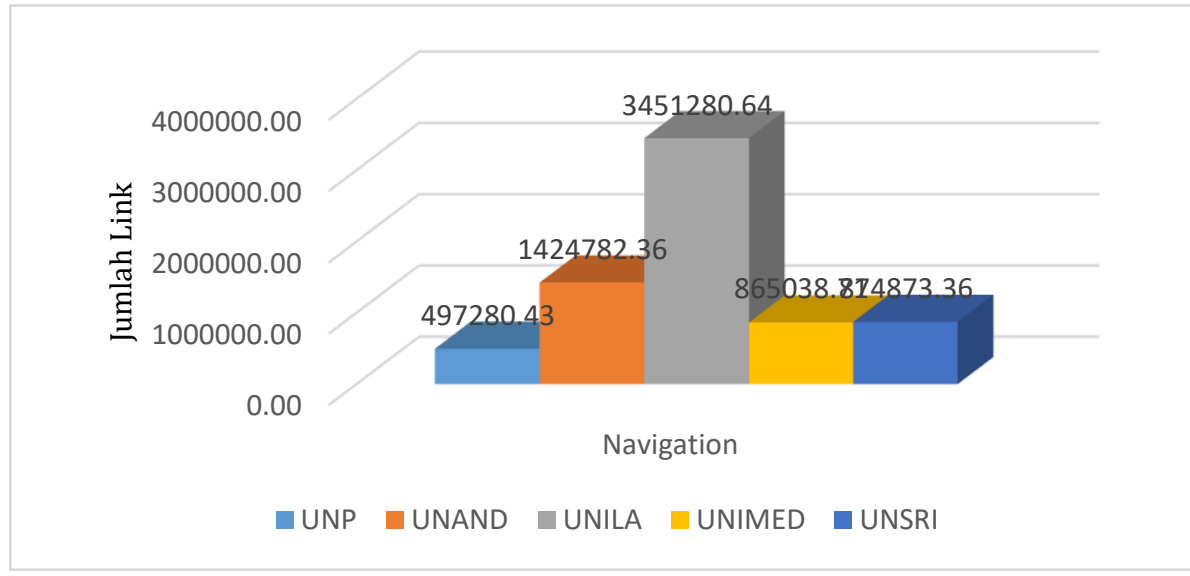

Gambar 6. Hasil Pengukuran Navigation

Berdasarkan gambar 7 dapat dilihat bahwa website Universitas Andalas paling baik untuk kriteria site content dengan jumlah file yang terkandung dalam website paling banyak dibandingkan website perguruan tinggi lainnya yaitu terdapat rata - rata 44837,54 file. Sedangkan website Universitas Negeri Padang memiliki jumlah rata - rata terendah dengan 10994,71 file yang berekstensi doc, pdf, atau ppt.

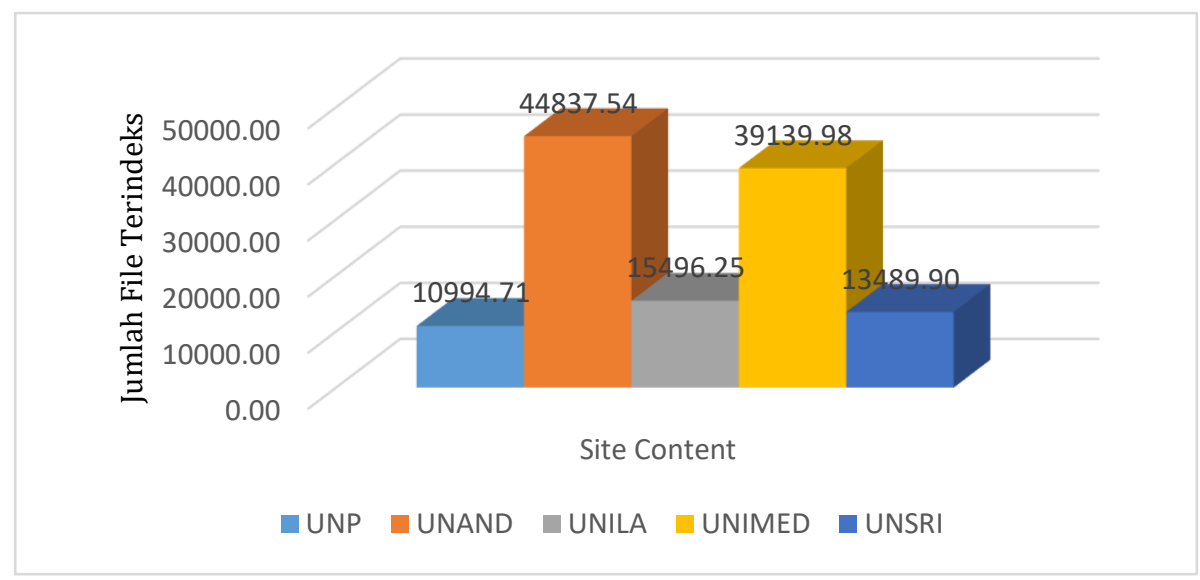

Gambar 7. Grafik Hasil Pengukuran Site Content

Data hasil pengukuran 7 kriteria dari 5 website Perguruan Tinggi kemudian dirangking menggunakan metode TOPSIS. Sebelum merangking data, ditentukan bobot dari setiap kriteria 
usability yang dapat dilihat pada Tabel. 2 yang merujuk pada nilai bobot kriteria pada penelitian sebelumnya[12].

Tabel 2. Nilai Bobot kriteria usability

\begin{tabular}{|l|c|}
\hline \multicolumn{1}{|c|}{ Kriteria } & Bobot \\
\hline Accessibility & 0,24 \\
\hline Personalization \& Customization & 0,15 \\
\hline Download Speed & 0,18 \\
\hline Ease of Use & 0,16 \\
\hline Error & 0,06 \\
\hline Navigation & 0,10 \\
\hline Site Content & 0,11 \\
\hline
\end{tabular}

Alternatif yang dipilih dalam metode TOPSIS mempunyai jarak terdekat dengan solusi ideal positif dan jeda terjauh dari solusi ideal negatif. Tabel tiga adalah hasil perangkingan dengan metode TOPSIS

Tabel 3. Rangking Alternatif

\begin{tabular}{|c|l|c|}
\hline Peringkat & \multicolumn{1}{|c|}{ Website } & $\mathrm{V}_{\mathrm{i}}$ \\
\hline 1 & Universitas Andalas (https://unand.ac.id/id/) & 0,707 \\
\hline 2 & Universitas Negeri Padang (https://unp.ac.id/) & 0,626 \\
\hline 3 & Universitas Negeri Medan (https://unimed.ac.id/) & 0,524 \\
\hline 4 & Universitas Lampung (https://www.unila.ac.id/) & 0,516 \\
\hline 5 & Universitas Sriwijaya (https://unsri.ac.id/) & 0,366 \\
\hline
\end{tabular}

Berdasarkan tabel 3 diatas dapat disimpulkan bahwa website Universitas Andalas memiliki usability paling baik dengan nilai kedekatan relatif terbesar dengan solusi ideal positif yaitu 0,707 disusul oleh Universitas Negeri Padang, Universitas Negeri Medan, Universitas Lampung, dan Universitas Sriwijaya yang memiliki kedekaan relatif dengan solusi ideal positif sebesar 0,366 .

Setelah melakukan perangkingan menggunakan metode TOPSIS, selanjutnya hasil perangkingan website perguruan tinggi di Sumatera menggunakan metode TOPSIS dari segi usability website dibandingkan dengan hasil perangkingan webometrics periode Januari 2022. Tabel 4 merupakan perbandingan hasil perangkingan menggunakan metode TOPSIS dengan webometrics.

Tabel 4. Rangking alternatif dengan TOPSIS dan webometrics

\begin{tabular}{|l|c|c|}
\hline \multirow{2}{*}{ Website Perguruan TInggi } & \multicolumn{2}{c|}{ Metode } \\
\cline { 2 - 3 } & TOPSIS & Webometrics \\
\hline UNAND & 1 & 2 \\
\hline UNP & 2 & 4 \\
\hline UNIMED & 3 & 5 \\
\hline UNILA & 4 & 1 \\
\hline UNSRI & 5 & 3 \\
\hline
\end{tabular}

Seperti yang tertera pada tabel empat bahwa rangking alternatif terdapat perbedaan dibandingkan dengan perangkingan webometrics. Perbedaan tersebut dapat terjadi oleh beberapa faktor, yaitu penelitian ini berfokus mengukur website perguruan tinggi dari segi usability website-nya dan proses perangkingan menggunakan metode TOPSIS. Webometrics menggunakan visibility (Jumlah external networks (subnet) yang terhubung dengan website perguruan tinggi), transparency (Jumlah sitasi dari top 210 penulis), dan excellence sebagai indikator untuk mendapatkan hasil perangkingan. 


\section{SIMPULAN DAN SARAN}

\section{Simpulan}

Berdasarkan penelitian ini dapat disimpulkan bahwa website perguruan tinggi di Sumatera diukur dari segi usability website metode TOPSIS dengan 7 kriteria, yaitu accessibility, personalization \& customization, download speed, ease of use, error, navigation, dan site content dalam tujuh hari pengumpulan data pada lima website perguruan tinggi, yaitu Universitas Negeri Padang, Universitas Andalas, Universitas Negeri Medan, Universitas Lampung, dan Universitas Sriwijaya menyatakan bahwa website Universitas Andalas memiliki usability website yang paling baik dengan nilai kedekatan relatif terbesar dengan solusi ideal positif yaitu 0,707 dibandingkan dengan empat website perguruan tinggi lainya disusul oleh UNP, UNIMED, UNILA, dan UNSRI.

\section{Saran}

Untuk penelitian selanjutnya memperpanjang durasi pengambilan data dan dilakukan secara berkala dengan memakai lebih banyak metode sehingga hasil perangkingan antar metode dapat dibandingkan.

\section{DAFTAR RUJUKAN}

[1] Byun, D. H. \& Finnie, G., "Evaluating usability, user satisfaction and intention to revisit for succesful e-government websites", Electronic Government, An International Journal, VIII(1), pp. 1-19, 2011

[2] Mike Thelwall, "Introduction to Webometrics: Quantitative Web Research for the Social Sciences”. Morgan \& Claypool. ISBN 9781598299946, 2009.

[3] Nielsen, J. 2003. Usability 101: Introduction to usability. Online http://www.nngroup.com/articles/usability-101-introduction-to-usability/. Diakses tanggal 28 Desember 2021.

[4] Inas Abuqaddom, Hadeel Alazzam \& Amjad Hudaib, "A measurable website usability model: Case Study University of Jordan", 2019 10th International Conference on Information and Communication Systems (ICICS), 2019

[5] Sukiman et al, "Decision Support System for Academic Administration Staff Achievement in STMIK IBBI Using TOPSIS-HFLTS Method", 2020 3rd International Conference on Mechanical, Electronics, Computer, and Industrial Technology (MECnIT), 2020

[6] Ramdania et al, "TOPSIS Method on Selection of New Employees' Acceptance", 978-17281-7596-6/20/\$31.00 2020 IEEE, 2020

[7] Yufika Sari Bagi, Suyono \& Michel Farrel Tomatala, "Decision Support System for High Achieving Students Selection Using AHP and TOPSIS", 2020 2nd International Conference on Cybernetics and Intelligent System (ICORIS), 2020

[8] S. Supraja, Dr. P. Kousalya, "A Comparative Study by AHP and TOPSIS for the Selection of All Round Excellence Award", International Conference on Electrical, Electronics, and Optimization Techniques (ICEEOT), 2016

[9] Irma Salamah, "Evaluasi Usability Website Polsri Dengan Menggunakan System Usability Scale", Jurnal Nasional Pendidikan Teknik Informatika Volume 8, Nomor 3, Desember 2019

[10] Yadi, “Analisa Usability Pada Website Traveloka”, Jurnal Ilmiah Betrik, Vol.09, No.02, Desember 2018

[11] Agus Setiawan, R. Arri Widyanto, "Evaluasi Website Perguruan Tinggi Menggunakan Metode Usability Testing”, Jurnal Informatika: Jurnal Pengembangan IT (JPIT), Vol.03, No.03, September 2018Mike Thelwall, "Introduction to Webometrics: Quantitative Web Research for the Social Sciences”. Morgan \& Claypool. ISBN 9781598299946, 2009. 
[12] Montenegro Villota, A. L, “Usability of Websites, University of Birningham”, 2009.

[13] Aisyah, S., Hetti, H, \& Bambang, P, "Analisis dan Evaluasi Aspek Usability Pada Web HRMIS Telkom University Menggunakan Usability Testing”. Bandung: Departemen Teknik Informatika Universitas Telkom, 2014.

[14] Pearson, J. M., A. Pearson, et al. "Determining the importance of key criteria in web usability." Management Research News 30(11): 816-828, 2007.

[15] Turban, E and Gehrke, D, "Determinants of e-commerce website". Human Systems Management, 19(2):111-120, 2000.

[16] Peters, Cara and David A. Bradbard. "Web accessibility: an introduction and ethical implications",2010.

[17] Palmer, J. W. "Web site usability, design, and performance metrics", Information systems research 13(2): 151-167, 2002. 